\title{
DYNAMIC ADAPTATION METHOD FOR NUMERICAL SOLUTION OF AXISYMMETRIC STEFAN PROBLEMS
}

\author{
V.I. MAZHUKIN ${ }^{1}$, M.M. CHUIKO ${ }^{2}$ and A.M. LAPANIK ${ }^{3}$ \\ 1 Institute of Mathematical Modelling, RAS \\ Miusskaya Sq. 4, 125047 Moscow, Russia \\ E-mail: immras@orc.ru \\ 2 Institute of Mathematics, NAS of Belarus \\ Surganov St. 11, 220072 Minsk, Belarus \\ E-mail: chuiko@im. bas-net.by \\ 3 Belarussian State University \\ Skoryna Ave. 4, 220050 Minsk, Belarus
}

Received October 10 2003; revised November 172003

\begin{abstract}
Application of the dynamic adaptation method for the numerical solution of multidimensional axisymmetric Stefan problems with explicit tracking of interfaces is presented. The dynamic adaptation method is based on the idea of transition of the physical coordinate system to the non-stationary coordinate system. The results of computational experiments for modelling the action of high energy fluxes on metals are given.
\end{abstract}

Key words: Stefan problem, curvilinear coordinate systems, adaptive method, melting, evaporation, difference scheme.

\section{INTRODUCTION}

Now-days laser technology is the widespread tool for the treatment of metals, dielectrics and semiconductors. Melting and evaporation are the basis of such technological operations as welding, drilling, surface modification and etc. In pulsed-laser material processing the phase transitions occur at very high rates. In this case a non-equilibrium phase-change kinetics becomes important [14].

One of the key techniques in study of laser influence on materials is mathematical modelling [4]. Mathematical description of such processes leads to the 
moving free-boundary problems for the heat diffusion [11]. Two approaches are widely used for numerical solution of the Stefan type problems: explicit tracking of moving interfaces $[1 ; 2]$ and using smoothing procedures $[7 ; 9 ; 13$; 15]. Dominant position of smoothing procedures in multidimensional problems is considerably connected with absence of effective methods for explicit tracking of moving interfaces. The smoothing algorithms don't allow for such physical effects as kinetics of phase transitions. In the problem of the pulsed action of high-energy fluxes on materials, where the nonequilibrium of fast phase transformations play a dominant role, it is necessary to locate explicitly the phase interfaces and take into account the related processes.

In present work the adaptive algorithm for solution of classical version of three-dimensional axisymmetric Stefan problem with explicit tracking of phase interfaces is considered. Two-interface Stefan problem in arbitrary twodimensional regions was solved by the dynamic adaptation method $[3 ; 6]$. This method is based on transformation of the initial coordinate system to the nonstationary curvilinear coordinate system. In this nonstationary boundary fitted coordinate system the interfaces coincide with the coordinate lines. In this case it is necessary to determine not only the value of the unknown functions (temperature fields) but also the coordinates of the grid points. The movement of the grid points is described by the partial differential equations added to the definition of problem.

\section{MATHEMATICAL MODEL}

The mathematical formulation of the classical version of three-dimensional axisymmetric Stefan problem, which describes melting and crystallization processes, is reduced to the quasi-linear heat transfer equation

$$
\begin{gathered}
{\left[\frac{\partial H}{\partial t}+\frac{\partial W_{1}}{\partial x}+\frac{\partial W_{2}}{\partial y}+\frac{\partial W_{3}}{\partial z}=g\right]_{m}, m=s, l,} \\
H=c_{p} \rho T, \quad W_{1}=-\lambda \frac{\partial T}{\partial x}, \quad W_{2}=-\lambda \frac{\partial T}{\partial y}, \quad W_{3}=-\lambda \frac{\partial T}{\partial z}
\end{gathered}
$$

in the region $\Omega_{x y z}$ with the axial symmetry (Fig.1a). An a priori unknown interface $\Gamma_{s l}(t)$ separates the solid $\Omega_{s}(t)$ and liquid $\Omega_{l}(t)$ phases: $\Omega_{x y z}=$ $\Omega_{s}(t) \cup \Omega_{l}(t)$. On $\Gamma_{s l}(t)$ the differential Stefan condition and the temperature continuity equation are fulfilled

$$
W_{l}^{n}-W_{s}^{n}=L_{m} \rho v_{s l}^{n}, \quad T_{s}=T_{l}=T_{m} .
$$

On the boundary $\partial \Omega_{x y z}$ of the region $\Omega_{x y z}$ the boundary conditions are specified in the form

$$
\left.(\mathbf{W}, \mathbf{n})\right|_{\partial \Omega_{x y}}=f
$$


where $\mathbf{n}$ is the external normal to $\partial \Omega_{x y z}, f$ is the function specified on $\partial \Omega_{x y z}$. Here $H$ is the enthalpy, $\mathbf{W}=\left(W_{1}, W_{2}, W_{3}\right)$ is the heat flow, $T_{m}, L_{m}$ are the temperature and the latent heat of melting (crystallization), $v_{s l}^{n}$ is the velocity of the motion of interface, subscripts $s, l$ refer to the solid and liquid phases, superscripts $n, \tau$ indicate normal and tangent components.

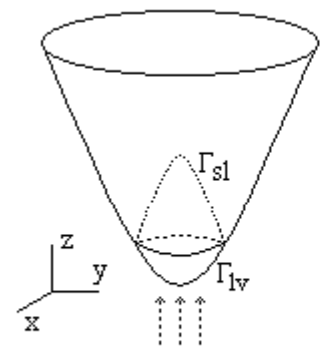

a)

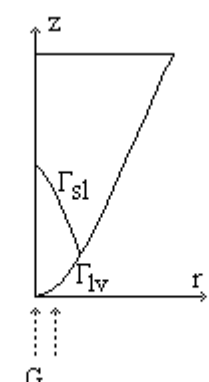

b)

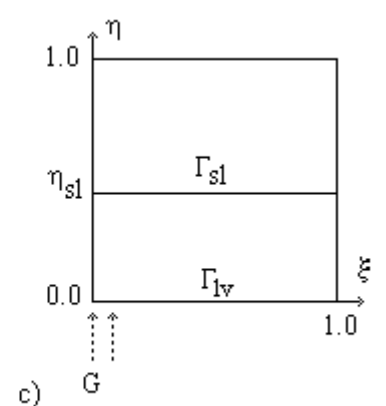

Figure 1. Domains of the problem definition.

The account of the evaporation leads to the appearance of the second movable interface $\Gamma_{l v}(t)$ on the boundary $\partial \Omega_{x y z}$. The process of advanced surface evaporation on this boundary is described by the mass, momentum and energy conservation laws

$$
\begin{aligned}
\rho_{l} v_{l v}^{n} & =\rho_{v}\left(u-v_{l v}^{n}\right), \\
P_{l}+\rho_{l}\left(v_{l v}^{n}\right)^{2} & =P_{v}+\rho_{v}\left(u-v_{l v}^{n}\right)^{2}, \\
-\lambda \frac{\partial T}{\partial n} & =G^{n}-L_{v} \rho_{l} v_{l v}^{n}
\end{aligned}
$$

and two additional relations describing the kinetics of phase transformations that are determined from the Knudsen layer approximation [5]

$$
T_{v}=T_{v}\left(T_{l}, \mathrm{M}\right), \quad \rho_{v}=\rho_{v}\left(\rho_{H}, \mathrm{M}\right)
$$

where $G=\left(G^{n}, G^{\tau}\right)$ is the energy source intensity, $u$ is the gas-dynamic velocity, $v_{l v}^{n}$ is the velocity of the evaporation front, $L_{v}$ is the heat of vaporization, $\mathrm{M}$ is the Mach number, and $\rho_{H}$ denotes the saturated vapor density. Here

$$
\mathrm{M}=\frac{u}{u_{c}}, \quad u_{c}=\left(\gamma R T_{v}\right)^{1 / 2} .
$$

The vapor temperature and density in (2.7) functionally depend on the 
Mach number $\mathrm{M}$, adiabat $\gamma$ and auxiliary parameter $m$

$$
\begin{aligned}
& T_{v}=T_{l} \frac{2 \gamma \mathrm{M}^{2}\left(m^{2}+0.5\right)^{2}}{\left(1+\gamma \mathrm{M}^{2}\right)^{2} m^{2} t^{2}} \\
& \rho_{v}=\rho_{H} \frac{1}{\exp \left(-m^{2}\right)+\pi^{1 / 2} m(1+\operatorname{erf}(m))} \frac{\left(1+\gamma \mathrm{M}^{2}\right) m^{2}}{\gamma \mathrm{M}^{2}\left(m^{2}+0.5\right)^{2}}
\end{aligned}
$$

For the known $\mathrm{M}$ the value of $m$ is determined from the equation

$$
F(\mathrm{M})\left(m^{2}+0.5\right)^{2}-m^{2}\left(m^{2}+1.5+\alpha\right)=0,
$$

where

$$
\begin{aligned}
& F(\mathrm{M})=1+\frac{3 \gamma \mathrm{M}^{2}-1}{\left(\gamma \mathrm{M}^{2}-1\right)^{2}}, \quad \alpha=2 t^{2}-0.5 \pi^{1 / 2} m t-1 \\
& t=\frac{2 m}{\pi^{1 / 2}}+\frac{1+\operatorname{erf}(m)}{\exp \left(-m^{2}\right)+\pi^{1 / 2} m(1+\operatorname{erf}(m))} \\
& \operatorname{erf}(m)=\frac{2}{\sqrt{\pi}} \int_{0}^{m} e^{-y^{2}} \mathrm{~d} y
\end{aligned}
$$

The value of $\rho_{H}$ is determined from the state equation

$$
\rho_{H}=\frac{P_{H}}{R T_{l}}, \quad P_{H}=P_{0} \exp \left(\frac{L_{v}}{R}\left(\frac{1}{T_{b}}-\frac{1}{T_{l}}\right)\right) .
$$

Here $P_{H}$ is the saturated vapor pressure, $P_{0}$ is the atmospheric pressure, $T_{b}$ is the boiling temperature, $R$ is the gas constant.

Due to axial symmetry of the problem in the cylindrical coordinate system $(r, \phi, z)$ the equation $(2.1)$ can be rewritten in the following form

$$
\begin{aligned}
& {\left[\frac{\partial H}{\partial t}+\frac{1}{r} \frac{\partial\left(r W_{r}\right)}{\partial r}+\frac{\partial W_{z}}{\partial z}=g\right]_{m},(r, z) \in \Omega_{r z}} \\
& W_{r}=-\lambda \frac{\partial T}{\partial r}, W_{z}=-\lambda \frac{\partial T}{\partial z}
\end{aligned}
$$

in two-dimensional domain $\Omega_{r z}$ with curvilinear boundary (Fig.1b). On the boundary $\partial \Omega_{r z}, r \neq 0$ the boundary conditions $(2.3)-(2.7)$ are defined, and at $r=0$ the condition $W_{r}=0$ is fulfilled.

\section{STEFAN PROBLEM IN NONSTATIONARY CURVILINEAR COORDINATE SYSTEM}

We introduce the nonstationary transformation

$$
\xi=\xi(r, z, t), \quad \eta=\eta(r, z, t)
$$


mapping physical domain with arbitrary shape $\Omega_{r z}$ onto the rectangle $\Omega_{\xi \eta}$ in the space of curvilinear coordinates $(\xi, \eta)$. Boundary $\partial \Omega_{\xi \eta}$ and interfaces $\Gamma_{s l}$ and $\Gamma_{l v}$ in $\Omega_{\xi \eta}$ coincide with the corresponding coordinate lines and are constant in time (Fig.1c).

The problem $(2.3)-(2.6),(2.13)$ can be written in an arbitrary curvilinear unsteady coordinate system $(\xi, \eta, t)$ as:

$$
\begin{gathered}
{\left[\frac{\partial(\psi H)}{\partial t}=\frac{1}{r}\left(-\frac{\partial}{\partial \xi}\left(\rho r W_{r} \frac{\partial z}{\partial \eta}\right)+\frac{\partial}{\partial \eta}\left(\rho r W_{r} \frac{\partial z}{\partial \xi}\right)\right)+\frac{\partial}{\partial \xi}\left(\rho W_{z} \frac{\partial r}{\partial \eta}\right)\right.} \\
-\frac{\partial}{\partial \eta}\left(\rho W_{z} \frac{\partial r}{\partial \xi}\right)+\frac{\partial}{\partial \xi}\left(-H Q_{r} \frac{\partial z}{\partial \eta}+H Q_{z} \frac{\partial r}{\partial \eta}\right) \\
\left.+\frac{\partial}{\partial \eta}\left(H Q_{r} \frac{\partial z}{\partial \xi}-H Q_{z} \frac{\partial r}{\partial \xi}\right)+\psi g\right]_{m}, \\
{\left[\frac{\partial r}{\partial t}=-\frac{Q_{r}}{\rho}\right]_{m}, \quad\left[\frac{\partial z}{\partial t}=-\frac{Q_{z}}{\rho}\right]_{m}, \quad m=s, l,}
\end{gathered}
$$

where

$$
\begin{gathered}
W_{r}=-\frac{\lambda \rho}{\psi}\left(\frac{\partial z}{\partial \eta} \frac{\partial T}{\partial \xi}-\frac{\partial z}{\partial \xi} \frac{\partial T}{\partial \eta}\right), \quad W_{z}=-\frac{\lambda \rho}{\psi}\left(-\frac{\partial r}{\partial \eta} \frac{\partial T}{\partial \xi}+\frac{\partial r}{\partial \xi} \frac{\partial T}{\partial \eta}\right), \\
\psi=\rho\left|J^{-1}\right|, \quad\left|J^{-1}\right|=\frac{\partial r}{\partial \xi} \frac{\partial z}{\partial \eta}-\frac{\partial r}{\partial \eta} \frac{\partial z}{\partial \xi} .
\end{gathered}
$$

The boundary condition on the $\Gamma_{s l}$, i.e., for $\left(\xi, \eta=\eta_{s l}\right) \in \Gamma_{s l}$, can be written in the form:

$$
\left[\left(-W_{r} \frac{\partial r}{\partial \xi}+W_{z} \frac{\partial z}{\partial \xi}\right)_{l}-\left(-W_{r} \frac{\partial z}{\partial \xi}+W_{z} \frac{\partial r}{\partial \xi}\right)_{s}\right]^{-\frac{1}{2}}=-L_{m} Q_{s l}^{n}
$$

and for $(\xi, \eta) \in \Gamma_{l v}$ we obtain:

$$
\begin{aligned}
& Q_{l v}^{n}=-\rho_{v}\left(u+\frac{Q_{l v}^{n}}{\rho_{l}}\right), \quad P_{l}+\frac{\left(Q_{l v}^{n}\right)^{2}}{\rho_{l}}=P_{v}+\rho_{v}\left(u+\frac{Q_{l v}^{n}}{\rho_{l}}\right)^{2} \\
& \left(-W_{r} \frac{\partial z}{\partial \xi}+W_{z} \frac{\partial r}{\partial \xi}\right)_{l} \gamma^{-\frac{1}{2}}=G^{n}+L_{v} Q_{l v}^{n}, \quad \eta=\mathrm{const}, \\
& \left(W_{r} \frac{\partial z}{\partial \eta}-W_{z} \frac{\partial r}{\partial \eta}\right)_{l} \alpha^{-\frac{1}{2}}=G^{n}+L_{v} Q_{l v}^{n}, \quad \xi=\mathrm{const},
\end{aligned}
$$

where $\alpha, \beta, \gamma$ are the components of metric tensor

$$
\alpha=\left(\frac{\partial r}{\partial \xi}\right)^{2}+\left(\frac{\partial z}{\partial \xi}\right)^{2}, \quad \beta=\frac{\partial r}{\partial \xi} \frac{\partial r}{\partial \eta}+\frac{\partial z}{\partial \xi} \frac{\partial z}{\partial \eta}, \quad \gamma=\left(\frac{\partial r}{\partial \eta}\right)^{2}+\left(\frac{\partial z}{\partial \eta}\right)^{2} .
$$




\section{FINITE DIFFERENCE SCHEME}

For the finite difference approximation of system (3.1) - (3.4) in the domain $\Omega_{\xi \eta} \times\left[0, t_{0}\right]$ we introduce the rectangular grid $\omega$ with the steps $h_{\xi}, h_{\eta}, \tau^{j}$.

The functions $r_{i, k}^{j}, z_{i, k}^{j}, Q_{r, i, k}^{j}, Q_{z, i, k}^{j}$ are determined in the grid nodes, while the functions $T_{i+1 / 2, k+1 / 2}^{j}, \psi_{i+1 / 2, k+1 / 2}^{j}, H_{i+1 / 2, k+1 / 2}^{j}$ are evaluated at the cell centers. The variables $W_{r, i+1 / 2, k}^{j}, W_{z, i+1 / 2, k}^{j}, W_{r, i, k+1 / 2}^{j}, W_{z, i, k+1 / 2}^{j}$ are evaluated at the centers of the cell edges.

Using the finite volume method [8], the initial differential problem is approximated by the implicit difference scheme:

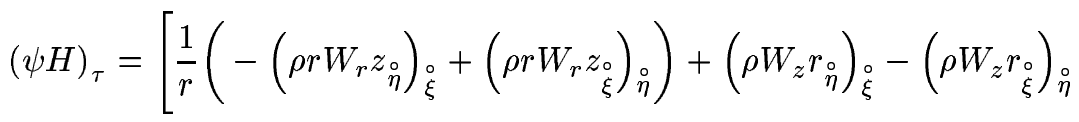

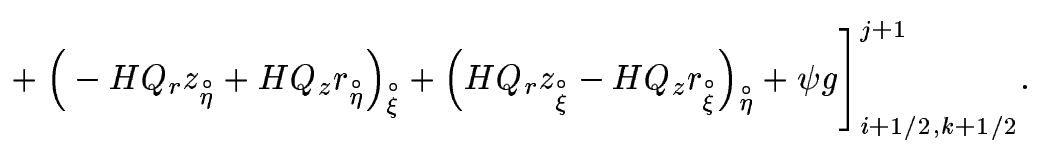

Here we use notations [8]:

$$
\begin{aligned}
& (\psi H)_{\tau}=\frac{(\psi H)_{i+1 / 2, k+1 / 2}^{j+1}-(\psi H)_{i+1 / 2, k+1 / 2}^{j}}{\tau^{j}},
\end{aligned}
$$

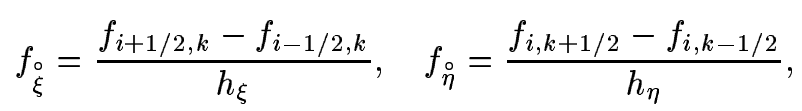

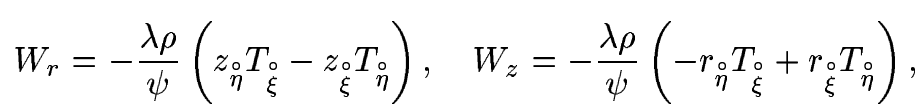

$$
\begin{aligned}
& \psi_{i+1 / 2, k+1 / 2}=\frac{\rho}{2 h_{\xi} h_{\eta}}\left\{\left(r_{i+1, k}-r_{i, k+1}\right)\left(z_{i+1, k+1}-z_{i, k}\right)\right. \\
& \left.-\left(r_{i+1, k+1}-r_{i, k}\right)\left(z_{i+1, k}-z_{i, k+1}\right)\right\} .
\end{aligned}
$$

The required interpolations are performed by the following formulas:

$$
\begin{aligned}
& H_{i, k+1 / 2}=0.5\left(H_{i+1 / 2, k+1 / 2}+H_{i-1 / 2, k+1 / 2}\right), \\
& H_{i+1 / 2, k}=0.5\left(H_{i+1 / 2, k+1 / 2}+H_{i+1 / 2, k-1 / 2}\right), \\
& Q_{i, k+1 / 2}=0.5\left(Q_{i, k+1}+Q_{i, k}\right), Q_{i+1 / 2, k}=0.5\left(Q_{i+1, k}+Q_{i, k}\right), \\
& r_{i+1 / 2, k+1 / 2}=0.25\left(r_{i, k}+r_{i, k+1}+r_{i+1, k}+r_{i+1, k+1}\right), \\
& z_{i+1 / 2, k+1 / 2}=0.25\left(z_{i, k}+z_{i, k+1}+z_{i+1, k}+z_{i+1, k+1}\right) .
\end{aligned}
$$

It is easy to prove that for sufficiently smooth solutions the approximation error is of order $O\left(\tau^{j}+|h|^{2}\right),|h|^{2}=h_{\xi}^{2}+h_{\eta}^{2}$. 


\section{ALGORITHM FOR SOLUTION OF THE DISCRETE PROB- LEM}

In order to implement the difference scheme the algorithm, based on two enclosed iteration cycles, is used at each level. In the first cycle, the velocities $Q_{i, k}$ of the grid nodes and their positions are determined by the values of the temperatures from the previous iteration. In the second cycle the temperature distribution in the domains $\Omega_{l}, \Omega_{s}$ are calculated.

The obtained systems of the linear algebraic equations is solved by the modified strongly implicit method [10].

Next we present the algorithm for an evaluation of parameters on the interface $\Gamma_{l v}(t)$ :

1. From equation (2.11) the parameter $m$ is evaluated by the Newton method.

2. From energy conservation law (2.6) the temperature values $T_{l}$ are evaluated. From equations (2.9) and (2.8) the values $T_{v}, u_{c}$ are determined, respectively.

3. The values of the pressure $P_{H}$ and saturated vapor density $\rho_{H}$ are evaluated from (2.12).

4. From (2.8) and mass conservation law (2.4) the gas-dynamic velocity $u$ and the velocity $v_{l v}^{n}$ of the interface $\Gamma_{l v}$ are obtained.

5. The vapor pressure is determined from the state equation $P_{v}=\rho_{v} R T_{v}$ and the pressure $P_{l}$ is obtained from momentum conservation law (2.5).

The values of normal component of mass flow on the interface $\Gamma_{l v}(t)$ at the cell edge midpoints are determined by the formula

$$
Q^{n}=-\rho_{l} v_{l v}^{n}
$$

and on the interface $\Gamma_{s l}(t)$ from the Stefan condition

$$
Q_{i+1 / 2, k}^{n}=L_{m}^{-1}\left[\left(W_{i+1 / 2, k}^{n}\right)_{s}-\left(W_{i+1 / 2, k}^{n}\right)_{l}\right], i=0, \cdots, I-1, k=k_{s l} .
$$

For the evaluation of the mass flow components $\mathbf{Q}_{i, k}$ in the interface nodes the mass conservation law

$$
S_{A B C D}=S_{A B E D}, S_{D F G H}=S_{D E G H}
$$

was used in the following form (see Fig. 2)

$$
\begin{aligned}
& \left(\mathbf{d}_{i, k}-\mathbf{d}_{i-1 / 2, k}\right) \times \mathbf{Q}_{i-1 / 2, k}=\left(\mathbf{d}_{i, k}-\mathbf{d}^{\prime}{ }_{i-1 / 2, k}\right) \times \mathbf{Q}_{i, k}, \\
& \left(\mathbf{d}_{i+1 / 2, k}-\mathbf{d}_{i, k}\right) \times \mathbf{Q}_{i+1 / 2, k}=\left(\mathbf{d}^{\prime}{ }_{i+1 / 2, k}-\mathbf{d}_{i, k}\right) \times \mathbf{Q}_{i, k}, \\
& i=1, \cdots, I-1, k=k_{s l} \text {, }
\end{aligned}
$$




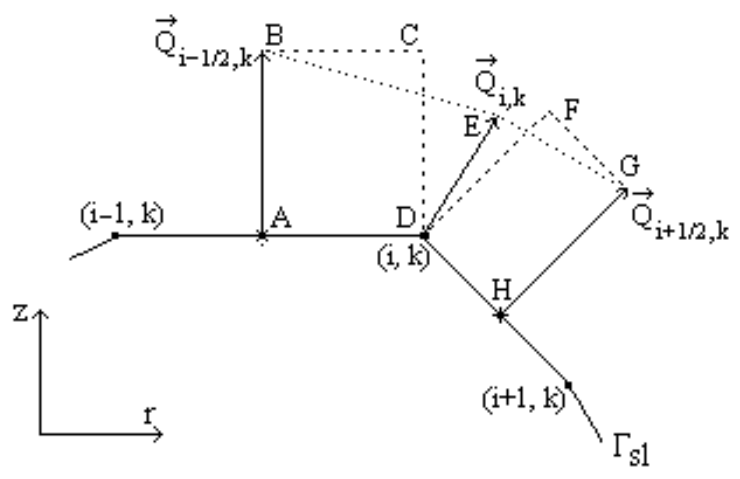

Figure 2. Definition of $\mathbf{Q}_{i, k}$ on the interface $\Gamma_{s l}$

where

$$
\begin{aligned}
& \mathbf{Q}_{i, k}=\left(Q_{r, i, k}, Q_{z, i, k}\right), \quad \mathbf{d}_{i, k}=\left(r_{i, k}, z_{i, k}\right), \\
& \mathbf{d}^{\prime}{ }_{i \pm 1 / 2, k}=\mathbf{d}_{i \pm 1 / 2, k}-\frac{\tau^{j}}{\rho} \mathbf{Q}_{i \pm 1 / 2, k} .
\end{aligned}
$$

For evaluation of $\mathbf{Q}_{0, k}, \mathbf{Q}_{I, k}$ at the boundary points of the interface the mass conservation law is written in the form

$$
\begin{aligned}
& \left(\mathbf{d}_{1 / 2, k}-\mathbf{d}_{0, k}\right) \times \mathbf{Q}_{1 / 2, k}=\left(\mathbf{d}_{1 / 2, k}^{\prime}-\mathbf{d}_{0, k}\right) \times \mathbf{Q}_{0, k} \\
& \left(\mathbf{d}_{0, k+1}-\mathbf{d}_{0, k}\right) \cdot \mathbf{Q}_{0, k}=0 \\
& \left(\mathbf{d}_{I, k}-\mathbf{d}_{I-1 / 2, k}\right) \times \mathbf{Q}_{I-1 / 2, k}=\left(\mathbf{d}_{I, k}-\mathbf{d}_{I-1 / 2, k}^{\prime}\right) \times \mathbf{Q}_{I, k} \\
& \left(\mathbf{d}_{I, k+1}-\mathbf{d}_{I, k}\right) \cdot \mathbf{Q}_{I, k}=0
\end{aligned}
$$

Here $\mathbf{a} \times \mathbf{b}$ and $\mathbf{a} \cdot \mathbf{b}$ are the vector and scalar products, respectively.

For a more regular distribution of nodes on the interface the tangential component of mass flow $Q_{i, k_{s l}}^{\tau}$ was evaluated. Finally, we get the following expression for the evaluation of mass flow on the solid-liquid interface:

$$
\mathbf{Q}_{i, k_{s l}}=Q_{i, k_{s l}}^{n} \cdot \mathbf{n}+Q_{i, k_{s l}}^{\tau} \cdot \boldsymbol{\tau}
$$

where $\mathbf{n}$ is the unit normal, $\boldsymbol{\tau}$ is the unit tangent vector.

For the redistribution of grid nodes inside subdomains $\Omega_{s}(t)$ and $\Omega_{l}(t)$ we use the equations (3.2) in the following form:

$$
\frac{\partial r}{\partial t}=\frac{D_{\xi}}{\alpha}\left(\left(\frac{\partial r}{\partial \xi}\right)^{2} \frac{\partial^{2} r}{\partial \xi^{2}}+\frac{\partial r}{\partial \xi} \frac{\partial z}{\partial \xi} \frac{\partial^{2} z}{\partial \xi^{2}}\right)+\frac{D_{\eta}}{\gamma}\left(\left(\frac{\partial r}{\partial \eta}\right)^{2} \frac{\partial^{2} r}{\partial \eta^{2}}\right.
$$




$$
\begin{gathered}
\left.+\frac{\partial r}{\partial \eta} \frac{\partial z}{\partial \eta} \frac{\partial^{2} z}{\partial \eta^{2}}\right)+\frac{D}{\left|J^{-1}\right|}\left(\alpha \frac{\partial^{2} r}{\partial \xi^{2}}-2 \beta \frac{\partial^{2} r}{\partial \xi \partial \eta}+\gamma \frac{\partial^{2} r}{\partial \eta^{2}}\right) \\
\frac{\partial z}{\partial t}=\frac{D_{\xi}}{\alpha}\left(\left(\frac{\partial z}{\partial \xi}\right)^{2} \frac{\partial^{2} z}{\partial \xi^{2}}+\frac{\partial r}{\partial \xi} \frac{\partial z}{\partial \xi} \frac{\partial^{2} r}{\partial \xi^{2}}\right)+\frac{D_{\eta}}{\gamma}\left(\left(\frac{\partial z}{\partial \eta}\right)^{2} \frac{\partial^{2} z}{\partial \eta^{2}}+\frac{\partial r}{\partial \eta} \frac{\partial z}{\partial \eta} \frac{\partial^{2} r}{\partial \xi^{2}}\right) \\
+\frac{D}{\left|J^{-1}\right|}\left(\alpha \frac{\partial^{2} z}{\partial \xi^{2}}-2 \beta \frac{\partial^{2} z}{\partial \xi \partial \eta}+\gamma \frac{\partial^{2} z}{\partial \eta^{2}}\right)
\end{gathered}
$$

These equations can be obtained from the principle of equidistribution of the grid points along coordinate lines $\xi=$ const and $\eta=$ const:

$$
\begin{aligned}
& \frac{\partial l_{\xi}}{\partial t}=-\frac{Q_{\xi}}{\rho}, \quad \frac{\partial l_{\eta}}{\partial t}=-\frac{Q_{\eta}}{\rho}, \\
& Q_{\xi}=-\rho D_{\xi} \frac{\partial^{2} l_{\xi}}{\partial \xi^{2}}, \quad Q_{\eta}=-\rho D_{\eta} \frac{\partial^{2} l_{\eta}}{\partial \eta^{2}},
\end{aligned}
$$

where $Q_{\xi}$ and $Q_{\eta}$ are contravariant components of the vector $\mathbf{Q}, D_{\xi}$ and $D_{\eta}$ are diffusion coefficients,

$$
l_{\xi}=\int_{0}^{\xi} \sqrt{\alpha} \mathrm{d} \xi, \quad l_{\eta}=\int_{0}^{\eta} \sqrt{\gamma} \mathrm{d} \eta
$$

are the lengths of coordinate lines $\eta=$ const and $\xi=$ const, respectively. Here Cartesian components $Q_{r}, Q_{z}$ and contravariant components $Q_{\xi}, Q_{\eta}$ of $\mathbf{Q}$ are connected by relations

$$
Q_{r}=\frac{1}{\sqrt{\alpha}} \frac{\partial r}{\partial \xi} Q_{\xi}+\frac{1}{\sqrt{\gamma}} \frac{\partial r}{\partial \eta} Q_{\eta}, \quad Q_{z}=\frac{1}{\sqrt{\alpha}} \frac{\partial z}{\partial \xi} Q_{\xi}+\frac{1}{\sqrt{\gamma}} \frac{\partial z}{\partial \eta} Q_{\eta} .
$$

The third term on the right-hand side of equations (5.1) was introduced in order to guaranty the smoothness of the coordinate lines.

The obtained system was approximated by the fully implicit difference scheme. For its implementation the following Picard type iteration process was used:

$$
\begin{aligned}
& \stackrel{s}{r}_{\tau}^{+1}=\frac{D_{\xi}}{\stackrel{s}{\alpha}}\left(\left(\stackrel{s}{r \xi}^{s}\right)^{2} \stackrel{s+1}{r_{\xi \xi}}+\stackrel{s+1}{r_{\xi}} z_{\xi} z_{\xi \xi}^{s}\right)+\frac{D_{\eta}}{\stackrel{s}{\gamma}}\left(\left(r_{\eta}^{s}\right)^{2} \stackrel{s}{r_{\eta \eta}+1}+\stackrel{s+1}{r_{\eta}} z_{\eta} z_{\eta \eta}^{s}\right)
\end{aligned}
$$

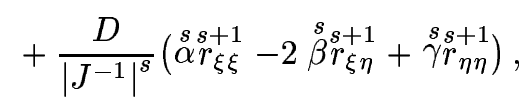

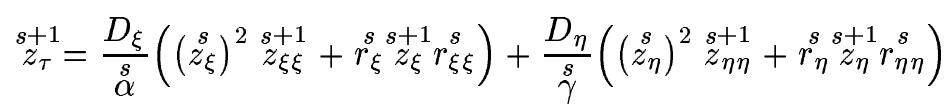

$$
\begin{aligned}
& +\frac{D}{\left|J^{-1}\right|^{s}}\left(\stackrel{s}{\alpha} z_{\xi \xi}^{s+1}-2 \stackrel{s}{\beta}{ }_{z \xi \eta}^{s+1}+\stackrel{s}{\gamma} z_{\eta \eta}^{s+1}\right) .
\end{aligned}
$$




\section{NUMERICAL EXPERIMENT}

The presented algorithm was applied to simulate the action of high energy fluxes on the spherical aluminum target with radius of $0.5 \mathrm{~cm}$. Two different source intensities $G=10^{5} \mathrm{~W} / \mathrm{cm}^{2}$ and $G=5 \cdot 10^{5} \mathrm{~W} / \mathrm{cm}^{2}$ were considered. The radius of focusing spot was $0.1 \mathrm{~cm}$. Analysis of the heating process leads to the identification of two distinct stages of heating. The first stage includes heating of the target without phase transformations. At this stage the domain is equal to the solid subdomain. The second stage includes heating with solidliquid and liquid-vapor transformations.
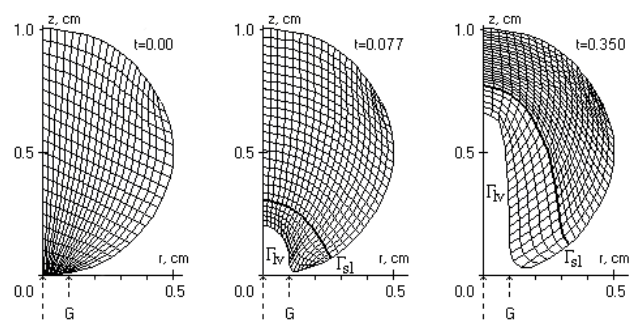

Figure 3. Computational grid in the physical space, $G=10^{5} \mathrm{~W} / \mathrm{cm}^{2}$
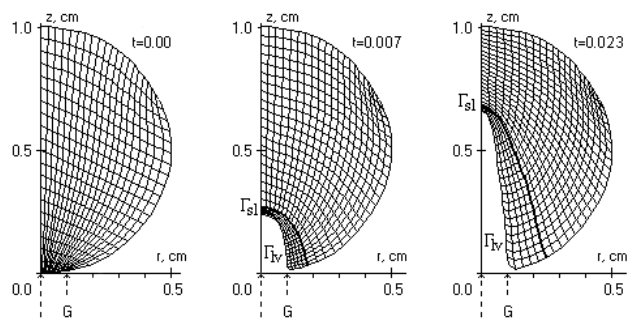

Figure 4. Computational grid in the physical space, $G=5 \cdot 10^{5} \mathrm{~W} / \mathrm{cm}^{2}$
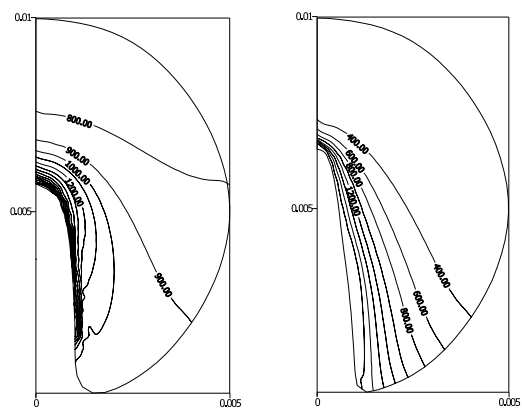

Figure 5. The distribution of temperature fields, $G=10^{5} \mathrm{~W} / \mathrm{cm}^{2}$ and $G=5 \cdot 10^{5} \mathrm{~W} / \mathrm{cm}^{2}$

During heating without phase transformations the grid with $21 \times 21$ fixed nodes was used. It was constructed by the elliptic grid generator [12]. 
The second stage begins when the equilibrium melting temperature $T_{m}=$ $933.3^{\circ} \mathrm{K}$ is reached on the irradiated surface. In order to introduce the liquid phase the overheat by $0.1^{\circ} \mathrm{K}$ was permitted. From the overheating energy and the latent heat $L_{m}$ the initial thickness of the liquid phase was determined and the new subdomain $\Omega_{l}, \Omega_{r z}=\Omega_{s} \cup \Omega_{l}$ was introduced. The new subgrid $21 \times 6$ was constructed for this subdomain. From that moment the grid was dynamically reconstructed at each time level, see Fig. $3-4$.

Continuation of the heating, conducted by the process of advanced surface evaporation, leads to the formation of a deep channel in the direct zone of the influence. Isotherms in Fig. 5 show the distribution of the temperature fields for different energy intensities. The thickness of the liquid phase for $G=5 \cdot 10^{5} \mathrm{~W} / \mathrm{cm}^{2}$ is less than one for $G=10^{5} \mathrm{~W} / \mathrm{cm}^{2}$. Maximum values of temperature on the energy-release surface were $3190^{\circ} \mathrm{K}$ and $2470^{\circ} \mathrm{K}$, respectively.

\section{REFERENCES}

[1] P.V. Breslavskii and V.I. Mazhukin. Mathematical modeling of pulse fluxing and evaporation processes of metal with explicit interface tracking. Inzh. Fiz. Journal, 57(1), $107-114,1989$. (in Russian)

[2] M. Davis, P. Kapadia and J. Dowden. Solution of a Stefan problem in the theory of laser welding by the method of lines. J. Comput. Phys, 60, 534-548, 1985.

[3] V. Mazhukin and M. Chuiko. Solution of the multi-interface Stefan problem by the method of dynamic adaptation. Comput. Meth. Appl. Math., 2, $283-294,2002$.

[4] V. Mazhukin and A. Samarskii. Mathematical modelling in the technology of laser treatments of material. Surv. Math. Ind., 4, 85 - 149, 1994.

[5] V.I. Mazhukin, P.A. Prudkovskii and A.A. Samohin. About gas-dynamical boundary conditions on the evaporation front. Matematicheskoe modelirovanie, 6(11), 3 - 10, 1994. (in Russian)

[6] V.I. Mazhukin, A.A. Samarskii and M.M. Chuiko. Dynamic adaptation method for nonstationary multidimensional Stefan problems. Doklady RAS, 368(3), 307 - 310, 1999. (in Russian)

[7] G.H. Meyer. The numerical solution of Stefan problems with front-tracking and smoothing methods. Appl. Math. Comput., 4, 283 -306, 1978.

[8] A.A. Samarskii. Theory of difference schemes. Moscow: Nauka, 1983. (in Russian)

[9] A.A. Samarskii and B.D. Moiseenko. Effective homogeneous scheme for multidimensional Stefan problem. J. Vychisl. Matem. i Matem. Fiz, 5(5), 816-827, 1965. (in Russian)

[10] G.E. Shneider and M. Zedan. A modified strongly implicit procedure for the numerical solution of field problems. Numer. Heat Transfer, 4, 1 - 19, 1981.

[11] D.A. Tarzia. A bibliography on FBP. The Stefan problem. MAT-Serie A, 2, 1 - 299, 2000.

[12] J.F. Thomson, Z.U.A. Warsi and C.W. Mastin. Boundary fitted coordinate systems for numerical solution of partial differential equations - a review. J. Comput. Phys, 47, 1 $-108,1982$.

[13] V.R. Voller, C.R. Swaminathan and B.G. Tomas. Fixed grid techniques for phase change problems: a review. Int. J. Numer. Methods Eng., 30, 875-898, 1990.

[14] G.-X. Wang and V. Prasad. Microscale heat and mass transfer and non-equilibrium 
phase change in rapid solidification. Materials Science and Engineering, 292, 142 $148,2000$.

[15] B.R.E. White. A modified finite difference scheme for the Stefan problem. Math. Comput., 41, 816 - 827, 1983.

Stefano uždavinio su ašine simetrija skaitinio sprendinio dinaminio adaptavimo metodas

V.I. Mazhukin, M.M. Chuiko, A.M. Lapanik

Straipsnyje nagrinėjamas Stefano daugiamečio uždavinio su ašine simetrija ir išreikštiniu sąlyčio pedsaku skaitinio sprendinio dinaminio adaptavimo metodas. Šis dinaminio adaptavimo metodas pagrịstas fizinių koordinačių transformacija ị nestacionarią kreivinę koordinačių sistemą. Šioje koordinačių sistemoje sąlytis sutampa su koordinacinèmis linijomis, ir reikalinga surasti ne tik nežinomas funkcijas, bet ir tinklo taškų koordinates. Tinklo taškų judejjimas aprašomas papildomomis diferencialinėmis lygtimis. Pateikti skaitinio modeliavimo pavyzdžiai metalo sąveikai su aukštos energijos srautais. 